D. Cozzone $\cdot$ C. Debard $\cdot$ N. Dif $\cdot$ N. Ricard $\cdot$ E. Disse $\cdot$

J. Vouillarmet $\cdot$ R. Rabasa-Lhoret $\cdot$ M. Laville •

D. Pruneau $\cdot$ J. Rieusset $\cdot$ E. Lefai $\cdot$ H. Vidal

\title{
Activation of liver $X$ receptors promotes lipid accumulation but does not alter insulin action in human skeletal muscle cells
}

Received: 21 September 2005 / Accepted: 14 November 2005 / Published online: 16 February 2006

C) Springer-Verlag 2006

\begin{abstract}
Aims/hypothesis: The aim of this study was to investigate the effects of liver $\mathrm{X}$ receptor (LXR) activation on lipid metabolism and insulin action in human skeletal muscle cells prepared from control subjects and from patients with type 2 diabetes. Subjects and methods: Cultured myotubes were obtained from muscle biopsies of 11 lean, healthy control subjects and ten patients with type 2 diabetes. The mRNA levels of LXR isoforms and lipogenic genes were estimated by RT-quantitative PCR, and the effects of LXR agonists on insulin action were evaluated by assays of protein kinase B serine 473 phosphorylation and glycogen synthesis. Results: Both LXR $\alpha$ and LXR $\beta$ were expressed in human skeletal muscle and adipose tissue and there was no difference in their mRNA abundance in tissues from patients with type 2 diabetes compared with control subjects. In cultured muscle cells, LXR activation by T0901317 strongly increased expression of the genes encoding lipogenic enzymes, including sterol regulatory element binding protein $1 \mathrm{c}$, fatty acid synthase and stearoyl-CoA desaturase 1 , and
\end{abstract}

D. Cozzone, C. Debard and N. Dif contributed equally to this work.

D. Cozzone - C. Debard - N. Dif - N. Ricard - E. Disse ·

J. Vouillarmet · R. Rabasa-Lhoret · M. Laville ·

J. Rieusset · E. Lefai · H. Vidal

INSERM U449, INRA U1235, Laennec Faculty of Medicine,

Claude Bernard University of Lyon,

Lyon, France

E. Disse $\cdot$ J. Vouillarmet $\cdot$ R. Rabasa-Lhoret $\cdot$ M. Laville Human Nutrition Research Center of Lyon,

Lyon, France

D. Pruneau

Department of Pharmacology, Fournier-Pharma,

Daix, France

H. Vidal $(\triangle)$

UMR INSERM U-449/INRA-1235,

Faculté de Médecine R Laennec,

Rue G. Paradin,

F-69372 Lyon Cedex 08, France

e-mail: vidal@sante.univ-lyon1.fr

Tel.: +33-478-778629

Fax: $+33-478-778762$ also promoted triglyceride accumulation in the presence of a high glucose concentration. Importantly, these effects on lipid metabolism did not affect protein kinase $\mathrm{B}$ activation by insulin. Furthermore, LXR agonists did not modify insulin action in muscle cells from patients with type 2 diabetes. Conclusions/interpretation: These data suggest that LXR agonists may lead to increased utilisation of lipids and glucose in muscle cells without affecting the mechanism of action of insulin. However, the long-term consequences of triglyceride accumulation in muscle should be evaluated before the development of effective LXR-based therapeutic agents.

Keywords Human muscle cells - Insulin action · Lipogenesis - Liver X receptor - SREBP1c promoter . Type 2 diabetes

Abbreviations FAS: fatty acid synthase - HKII: hexokinase II - LXR: liver X receptor - LXRE: liver X receptor-responsive element $\cdot \mathrm{PKB}$ : protein kinase $\mathrm{B}$. RT-qPCR: RT-quantitative PCR - SCD1: stearoyl-CoA desaturase 1 - SREBP1: sterol regulatory element binding protein 1

\section{Introduction}

Alterations of the main lipid metabolic pathways in skeletal muscle, characterised by reduced ability to oxidise fatty acids and the intramyocellular accumulation of triglycerides, are features of insulin resistance in type 2 diabetes mellitus [1-3]. Recent data have led to the hypothesis that these alterations of lipid metabolism play a central role in the defective action of insulin in skeletal muscle, probably through inhibition of the IRS1-dependent signalling pathway $[4,5]$.

Liver X receptors (LXR) $\alpha$ and $\beta$, encoded by the genes $N R 1 H 3$ and $N R 1 H 2$, respectively, are members of the nuclear receptor family and have been shown to be involved in the control of lipid and cholesterol metabolism [6]. LXR ligands are considered to be potential therapeutic 
agents and it has been demonstrated that treatment with the LXR agonist GW3965 improves glucose tolerance in a murine model of diet-induced obesity and insulin resistance [7]. Although LXRs are mainly present in the liver, significant expression in other tissues, including skeletal muscle, has been reported $[8,9]$.

Among the targets of the LXRs is the gene SREBF1, which encodes the transcription factor sterol regulatory element binding protein 1 (SREBP1)c [10], and has been implicated in the transcriptional action of insulin [11-13]. LXR-responsive elements (LXRE) are present in the SREBP1c promoter region of SREBF1 [14] and synthetic LXR agonists upregulate SREBP1c mRNA levels in rodents both in vivo and in vitro $[10,14,15]$. It is known that SREBP1c expression is decreased in the adipose tissue and skeletal muscle of insulin-resistant patients with type 2 diabetes [16]. The contribution of an alteration in the expression of the LXRs in the tissues of these patients has not yet been investigated.

Given the interest in LXR ligands as potential therapeutic agents and the role of SREBP1c in insulin action, it was important to better characterise the effects of LXR stimulation on insulin signalling and metabolic action. Indeed, activation of LXR may restore SREBP1c levels in diabetic tissues and thus increase insulin action; this is supported by experiments showing that adenovirusmediated overexpression of SREBP1c improved glycaemic control in insulin-deficient mice [17] and mimicked insulin action in rat myotubes [18]. However, LXR activation is well known to promote lipogenesis and triglyceride accumulation $[8,19,20]$. Intracellular accumulation of lipids is associated with reduced insulin efficiency in cell models $[4,21]$ and with insulin resistance in vivo $[2,4,5]$. Reconciliation of these two opposite effects of LXR activation needs to be clarified. We therefore investigated the effects of LXR agonists on lipid metabolism and insulin action in primary cultures of differentiated human skeletal muscle cells. The specific goals of this work were: (1) to verify whether the expression of the LXR isoforms is altered in the skeletal muscle and adipose tissue of patients with type 2 diabetes; (2) to study the effects of LXR activation by synthetic ligands on lipogenesis in cultured myotubes from control subjects; and (3) to find out whether LXR agonists can improve insulin action in muscle cells from patients with type 2 diabetes.

\section{Subjects and methods}

\section{Subjects}

All participants gave their written consent after being informed of the nature, purpose and possible risks of the study. The experimental protocol was approved by the Ethical Committees of the Hospices Civils de Lyon and performed according to French legislation (Huriet law).

For the study of SREBP1c, SREBP1a, LXR $\alpha$ and LXR $\beta$ mRNA expression in muscle and adipose tissue, 11 healthy lean volunteers and ten age-matched patients with type 2 diabetes were enrolled. Their characteristics are presented in Table 1. None of the healthy lean subjects had impaired glucose tolerance or a family or personal history of diabetes, obesity, dyslipidaemia or hypertension. To determine the action of insulin on glucose metabolism, the subjects were submitted to a 3-h euglycaemic-hyperinsulinaemic clamp with an insulin infusion rate of $2 \mathrm{mU} \mathrm{kg}^{-1}$ $\min ^{-1}$, as described previously in detail $[16,22]$. The expression of the target mRNAs was determined in skeletal muscle (vastus lateralis) biopsies (about $80 \mathrm{mg}$ wet weight) and in subcutaneous abdominal fat samples (about $150 \mathrm{mg}$ wet weight) taken under local anaesthesia before the hyperinsulinaemic clamp, in a fasted condition [16].

For the culture of skeletal muscle cells (myotubes), muscle biopsies (about $200 \mathrm{mg}$ wet weight) were taken under local anaesthesia from the vastus lateralis muscle in additional groups of subjects. This part of the study included 11 lean healthy control subjects (six men, five women, age $47 \pm 6$ years, BMI $23.8 \pm 0.9 \mathrm{~kg} / \mathrm{m}^{2}$, fasting plasma glucose $5.0 \pm 0.2 \mathrm{mmol} / 1$, fasting plasma insulin $6 \pm 1 \mathrm{mU} / \mathrm{l}$ ) with no family or personal history of diabetes, dyslipidaemia or hypertension, and of ten moderately obese patients with type 2 diabetes (five men, five women, age $56 \pm 3$ years, BMI $32.9 \pm 1.7 \mathrm{~kg} / \mathrm{m}^{2}$, fasting plasma glucose $9.6 \pm 0.9 \mathrm{mmol} / \mathrm{l}$, fasting plasma insulin $14 \pm 1 \mathrm{mU} / 1$, glycated $\mathrm{HbA}_{1 \mathrm{c}} 9.1 \pm 0.5 \%$, duration of diabetes $12 \pm 3$ years). None of the control subjects was taking medication other than oral contraceptive agents. The patients with type 2 diabetes were treated with oral hypoglycaemic agents (metformin and sulfonylurea).
Table 1 Characteristics of the subjects

${ }^{\mathrm{a}} p<0.001$ and ${ }^{\mathrm{b}} p<0.05$ for difference between type 2 diabetic patients and control subjects

\begin{tabular}{lll}
\hline & Control $(n=11)$ & Type 2 diabetes $(n=10)$ \\
\hline Sex $(\mathrm{M} / \mathrm{F})$ & $6 / 5$ & $5 / 5$ \\
Age $($ years) & $47 \pm 6$ & $56 \pm 3$ \\
BMI $\left(\mathrm{kg} / \mathrm{m}^{2}\right)$ & $23.8 \pm 0.9$ & $32.9 \pm 1.7^{\mathrm{a}}$ \\
Fasting glycaemia $(\mathrm{mmol} / \mathrm{l})$ & $4.7 \pm 0.1$ & $11.5 \pm 0.1^{\mathrm{a}}$ \\
Fasting insulinaemia $(\mathrm{mU} / \mathrm{l})$ & $6 \pm 1$ & $14 \pm 1^{\mathrm{a}}$ \\
Plasma NEFA ( $\mu \mathrm{mol} / \mathrm{l})$ & $483 \pm 67$ & $699 \pm 65^{\mathrm{b}}$ \\
Plasma triglycerides $(\mathrm{mmol} / \mathrm{l})$ & $675 \pm 93$ & $2067 \pm 245^{\mathrm{a}}$ \\
Basal glucose disposal rate $\left(\mathrm{mg} \mathrm{kg}^{-1} \mathrm{~min}^{-1}\right)$ & $2.3 \pm 0.1$ & $2.4 \pm 0.1$ \\
Insulin-induced glucose disposal rate $\left(\mathrm{mg} \mathrm{kg}^{-1} \mathrm{~min}^{-1}\right)$ & $10.6 \pm 0.8$ & $3.7 \pm 0.7^{\mathrm{a}}$ \\
\hline
\end{tabular}


Culture of human skeletal muscle cells

Differentiated myotubes were prepared according to the procedure previously described in detail [23, 24], after selection of the myoblasts using a monoclonal antibody (5.1H11; Developmental Studies Hybridoma Bank, Iowa City, IA, USA) combined with magnetic beads. The myoblasts were cultured in a Primaria flask (Falcon; Becton Dickinson, Bedford, MA, USA) in a growth medium composed of Ham's F10 supplemented with $2 \%$ Ultroser G (BioSepra, Cergy-Saint-Christophe, France), $2 \%$ fetal bovine serum (Invitrogen, Cergy Pontoise, France) and 1\% antibiotics (Invitrogen). At confluence, differentiation into myotubes was induced by changing the medium to Dulbecco's modified Eagle's medium supplemented with $2 \%$ horse serum (Hyclone, Logan, UT, USA), $2 \%$ fetal bovine serum and $1 \%$ antibiotics. Four days after initiation of differentiation, cells showed polynucleated status and expressed specific markers of human skeletal muscle, such as creatine kinase, sarcomeric $\alpha$-actin and myosin. In agreement with other studies [23-26], the rates of myoblasts' growth and fusion into myotubes were similar, and there was no apparent morphological difference, among cultured skeletal muscle cells from control subjects and patients with type 2 diabetes.

Products and incubation conditions

The synthetic LXR agonists T0901317 and GW3965 were obtained from Fournier-Pharma. Insulin was purchased from Sigma (L'isle d'Abeau, France). Differentiated myotubes were preincubated for $12 \mathrm{~h}$ in serum-free medium before addition of drugs or insulin. LXR agonists $(1 \mu \mathrm{mol} / \mathrm{l})$ were added for $6 \mathrm{~h}$ when studying the regulation of gene expression or for $48 \mathrm{~h}$ when investigating their effects on metabolism and on insulin signalling. Control incubations with $0.1 \%$ DMSO (vehicle) were made in parallel.

\section{Quantification of messenger RNAs}

Total RNA from skeletal muscle biopsies was prepared according to a procedure based on the method of Chomczynski and Sacchi, as described [27]. Total RNA from adipose tissue samples and from differentiated myotubes was prepared using the RNeasy kit (Qiagen, Courtaboeuf, France). The mRNA concentrations of the target genes were determined by RT-quantitative PCR (RTqPCR) using a Light-Cycler (Roche Diagnostics, Meylan, France), as previously described in detail [28]. A list of the primers and real-time PCR assay conditions is available upon request (http://www.vidal@sante.univ-lyon1.fr). The results were normalised using the concentration of hypoxanthine guanine phosphoribosyl transferase (HPRT) mRNA, measured as a reference gene in each sample using RT-qPCR.
Analysis of the human SREBP1c gene promoter

A human genomic clone (NR1-B022) which contains NotI flanking regions corresponding to the SREBP1c promoter was obtained from Zabarovsky et al. [29] and subcloned into the luciferase reporter gene vector pGL3-Enhancer (Promega, Charbonnières, France). HEK293 cells were maintained in serum-free medium for $18-24 \mathrm{~h}$ before transfection using Exgen 500 reagent (Euromedex, Souffelweyersheim, France) according to the manufacturer's instructions. Each culture well received $500 \mathrm{ng}$ of a given SREBP1c promoter/luciferase gene construct mixed with $1 \mathrm{ng}$ of pRL-CMV vector (Promega). Six hours after transfection, the cells were incubated with T0901317 ( $1 \mu \mathrm{mol} / 1$ ) or $0.1 \%$ DMSO (vehicle) for $24 \mathrm{~h}$. Firefly and Renilla activities (Dual-Luciferase Reporter Assay System; Promega) were measured using a TD-20/20 luminometer (Turner Designs, Sunnyvale, CA, USA).

\section{Determination of phosphorylated PKB}

Myotubes were lysed at $4^{\circ} \mathrm{C}$ in $200 \mathrm{mmol} / 1 \mathrm{NaF}, 20 \mathrm{mmol} / 1$ $\mathrm{NaH}_{2} \mathrm{PO}_{4}, 150 \mathrm{mmol} / \mathrm{l} \mathrm{NaCl}, 50 \mathrm{mmol} / 1 \mathrm{HEPES}, 4 \mathrm{mmol} / \mathrm{l}$ $\mathrm{NaVO}_{4}, 10$ mmol/1 EDTA, 1\% Triton X, 10\% glycerol and $2 \mathrm{mmol} / \mathrm{l}$ phenylmethyl sulfonyl fluoride. Proteins $(40 \mu \mathrm{g})$ were separated by SDS-PAGE. After transfer, phosphorylated protein kinase $\mathrm{B}(\mathrm{PKB})$ was detected using an antiphospho-Ser ${ }^{473}$ antibody (Upstate Biotechnology, Lake Placid, NY, USA) as previously described [24]. To normalise for equal protein amount, the blots were stripped and probed again with anti-PKB antibody (Upstate Biotechnology).

Determination of lipid accumulation in muscle cells

Cells were cultured for $48 \mathrm{~h}$ in a serum-free medium in the presence of T0901317 (1 $\mu \mathrm{mol} / \mathrm{l})$. During the last $24 \mathrm{~h}$ of the treatment, the glucose concentration in the medium was either maintained at $5 \mathrm{mmol} / \mathrm{l}$ or increased to $25 \mathrm{mmol} / \mathrm{l}$. Lipid accumulation was detected in myotubes using Oil Red-O staining following fixation in 3\% paraformaldehyde.

Measurement of insulin-induced glycogen synthesis

After $48 \mathrm{~h}$ of incubation with T0901317 (1 $\mu \mathrm{mol} / \mathrm{l})$, myotubes were treated for $90 \mathrm{~min}$ with or without $100 \mathrm{nmol} / 1$ insulin. Cells were then incubated for $3 \mathrm{~h}$ in $5 \mathrm{mmol} / \mathrm{l}$ glucose DMEM, supplemented with $12.5 \mathrm{mmol} / \mathrm{l}$ HEPES and containing $37 \mathrm{kBq} / \mathrm{ml}\left[\mathrm{U}^{14} \mathrm{C}\right.$ ] D-glucose (PerkinElmer, Courtaboeuf, France). After incubation, cells were washed twice with PBS and scraped in PBS supplemented with $0.1 \%$ SDS. Aliquots of the lysates were assayed for protein content with the Bio-Rad assay (BioRad, Marnes-la-Coquette, France). Glycogen was extracted as described [30] and the amount of $\left[{ }^{14} \mathrm{C}\right]$ glucose 
incorporated into glycogen was determined by scintillation counting.

\section{Statistical analysis}

All data in the text and figures are presented as mean \pm SE. The statistical significance of the results was determined using the non-parametric Mann-Whitney test when comparing data from controls and patients with type 2 diabetes, and the paired $t$-test when comparing the effects of the treatments. The threshold for significance was set at $p<0.05$.

\section{Results}

LXR and SREBP1 expression in skeletal muscle and adipose tissue of patients with type 2 diabetes

The patients with type 2 diabetes included in the study had classical metabolic characteristics, as presented in Table 1. In the basal state, after an overnight fast, their plasma concentrations of glucose, insulin, NEFA and triglycerides were higher than in a group of sex- and age-matched lean control subjects. Estimation of insulin sensitivity using euglycaemic-hyperinsulinaemic clamp showed that the
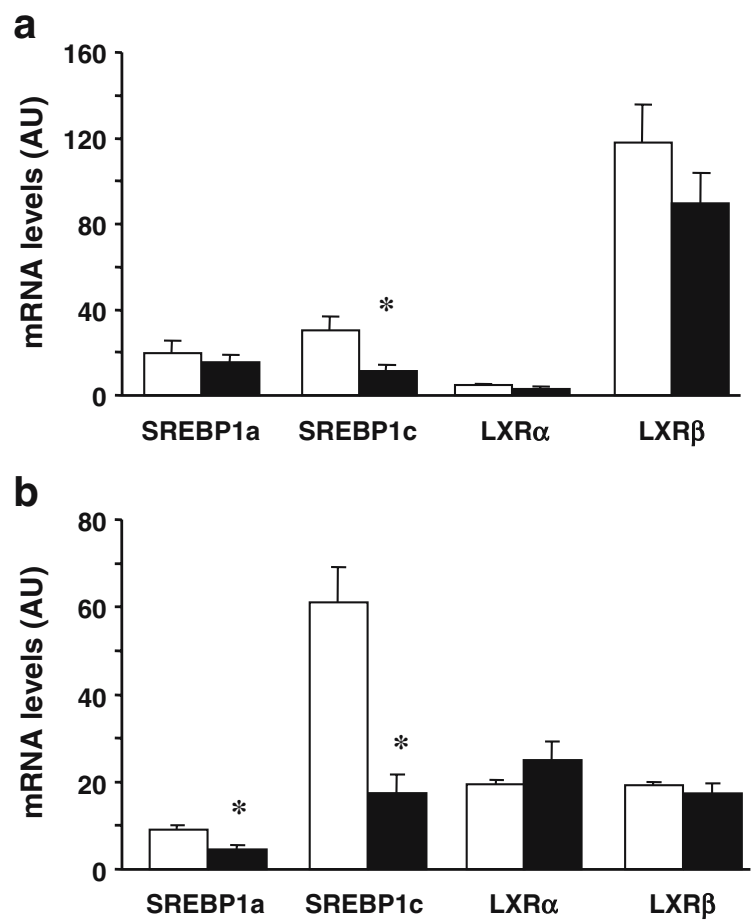

Fig. 1 Levels of SREBP1 and LXR isoforms mRNA in skeletal muscle and adipose tissue of patients with type 2 diabetes. The mRNA expression of SREBP1c and $1 \mathrm{a}$ and LXR $\alpha$ and $\beta$ was determined by quantitative real-time PCR in skeletal muscle (a) and adipose tissue (b). Tissues were obtained from healthy subjects (white bars) or patients with type 2 diabetes (black bars). Data are presented as mean \pm SE. ${ }^{*} p<0.05$ vs. healthy subjects. $A U$, Arbitrary units stimulation by insulin of whole-body glucose utilisation was reduced in the diabetic patients.

The basal concentrations of SREBP1a, SREBP1c, LXR $\alpha$ and LXR $\beta$ mRNAs in vastus lateralis muscle were determined using real-time RT-qPCR (Fig. 1). Type 2 diabetic patients were characterised by a significant reduction in the mRNA levels of SREBP1c. In contrast, the expression of SREBP1a was not altered. At the mRNA level, LXR $\beta$ was about 30 -fold more abundant than LXR $\alpha$ in human muscle (Fig. 1). There was no difference in the expression levels of these nuclear receptors between the control subjects and the subjects with type 2 diabetes.

In adipose tissue, the two LXR isoforms were expressed at similar levels and, as for muscle, no difference was observed between control subjects and patients with type 2 diabetes (Fig. 1). Regarding the SREBP1 transcripts, a dramatic reduction in the steady-state mRNA levels of SREBP1c characterised the adipose tissue of the patients with diabetes. SREBP1a was expressed at a lower level than SREBP1c (about six times less) and its mRNA abundance was also significantly decreased in fat samples of diabetic subjects (Fig. 1). There was no correlation between SREBP1c mRNA levels and the expression of the LXR transcripts in muscle or in adipose tissue (data not shown).

\section{a}
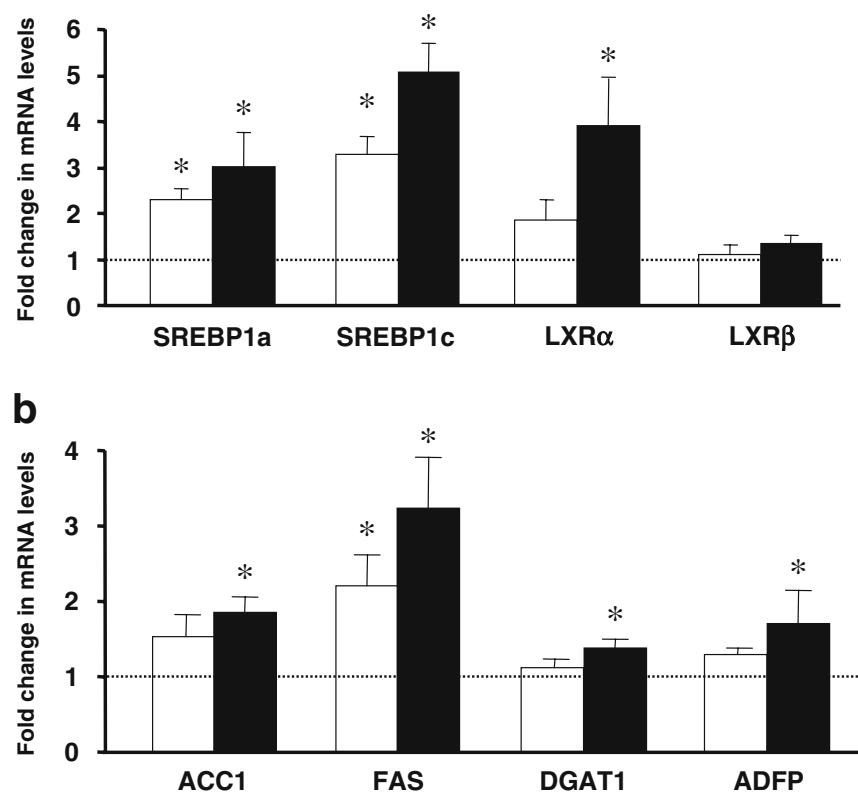

Fig. 2 Effect of LXR agonist on the mRNA levels of SREBP1, LXR and lipogenic enzymes in human myotubes. Differentiated myocytes were obtained from vastus lateralis skeletal muscle biopsies from healthy subjects and incubated with T0901317 ( $1 \mu \mathrm{mol} / \mathrm{l}$ ) in medium containing $5 \mathrm{mmol} / 1$ glucose for $6 \mathrm{~h}$ (white bars) or $48 \mathrm{~h}$ (black bars). Each time-point has a corresponding DMSO control condition (vehicle alone). The mRNA levels were determined by quantitative real-time PCR. Data are expressed as fold change compared with the untreated condition and are mean \pm SE $(n=5) .{ }^{*} p<0.05$ vs. vehicle alone. ACC1 Acetyl-CoA carboxylase $1, F A S$ fatty acid synthase, DGAT1 diacylglycerol, $O$-acetyltransferase 1, ADFP adipose differentiation-related protein 


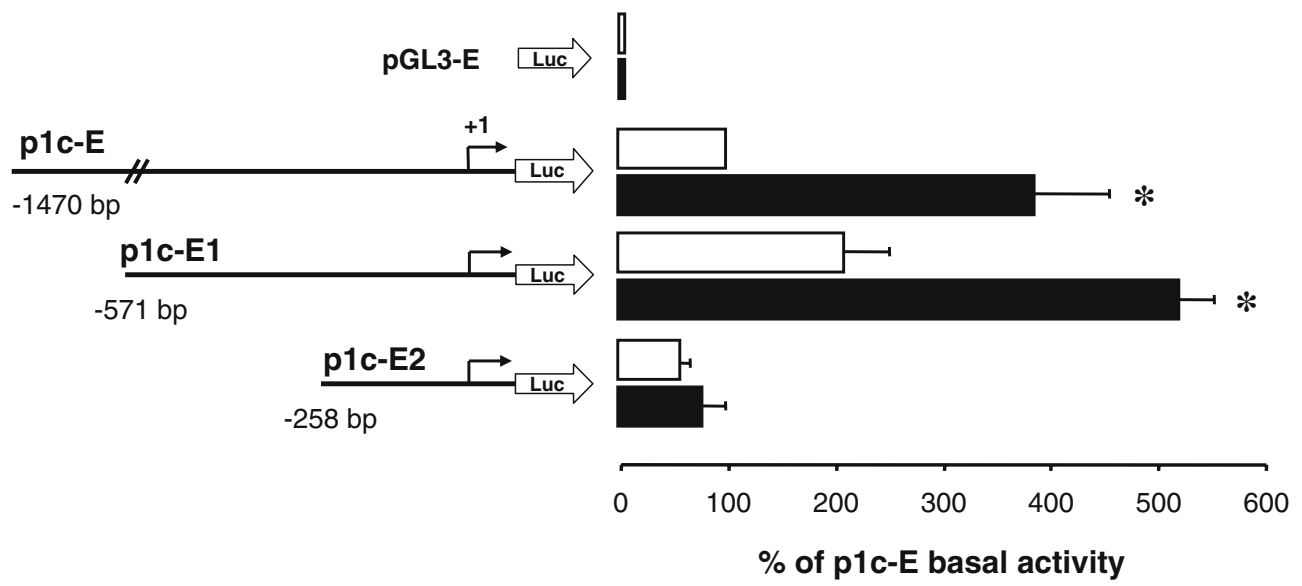

Fig. 3 Effect of LXR agonist on SREBF1 promoter activity. HEK 293 cells were transfected with a luciferase reporter gene driven by different constructs of the SREBP1c-specific region of the human SREBF1 gene, and treated with DMSO (white bars) or with $1 \mu \mathrm{mol} / 1$ T0901317 (black bars) for $24 \mathrm{~h}$. Relative luciferase activity was

LXR activation by T0901317 increased lipogenic gene expression and triglyceride accumulation in human muscle cells

Figure 2 shows the changes in the mRNA levels of SREBP1 and LXR isoforms and of key genes of lipogenesis in myotubes from control subjects incubated for 6 and $48 \mathrm{~h}$ with T0901317 $(1 \mu \mathrm{mol} / \mathrm{l})$. LXR activation produced a strong induction of SREBP1a and SREBP1c transcripts, readily measurable after $6 \mathrm{~h}$ of treatment. To ensure that the effect of T0901317 on SREBP1c expression was direct transcriptional activation through LXR activation, luciferase reporter constructs of the human gene promoter were transiently transfected into HEK293 cells. Figure 3 clearly shows that the addition of T0901317 ( $1 \mu \mathrm{mol} / \mathrm{l})$ strongly calculated using a dual luciferase assay. The two putative LXR responsive elements $(-311 /-296$ and $-260 /-245)$ were deleted in the p1c-E2 construct. Data are expressed with reference to the basal luciferase activity of plc-E and are mean \pm SE $(n=3) .{ }^{*} p<0.05$ in the presence of T0901317 vs. basal condition (DMSO)

increased luciferase activity. The deletion of a sequence containing the two neighbouring LXREs $(-311 /-296$ and $-260 /-245)$ totally suppressed the effect of T0901317.

T0901317 also strongly increased LXR $\alpha$ mRNA levels in human myotubes whereas there was no effect on the expression of LXR $\beta$ (Fig. 2). It is important to note that the mRNA concentrations of the two LXR isoforms in cultured myotubes in the basal condition $(1.5 \pm 0.2$ and $12.6 \pm 1.4 \mathrm{amol} / \mu \mathrm{g}$ total RNA for $\operatorname{LXR} \alpha$ and $\operatorname{LXR} \beta$ respectively) were similar to what was observed in vivo in skeletal muscle (Fig. 1). Regarding the genes of the lipogenic pathway, Fig. 2 also shows that all the tested genes were induced after $48 \mathrm{~h}$ of incubation with T0901317. Fatty acid synthase (FAS) mRNA expression displayed the greatest response, with a significant effect

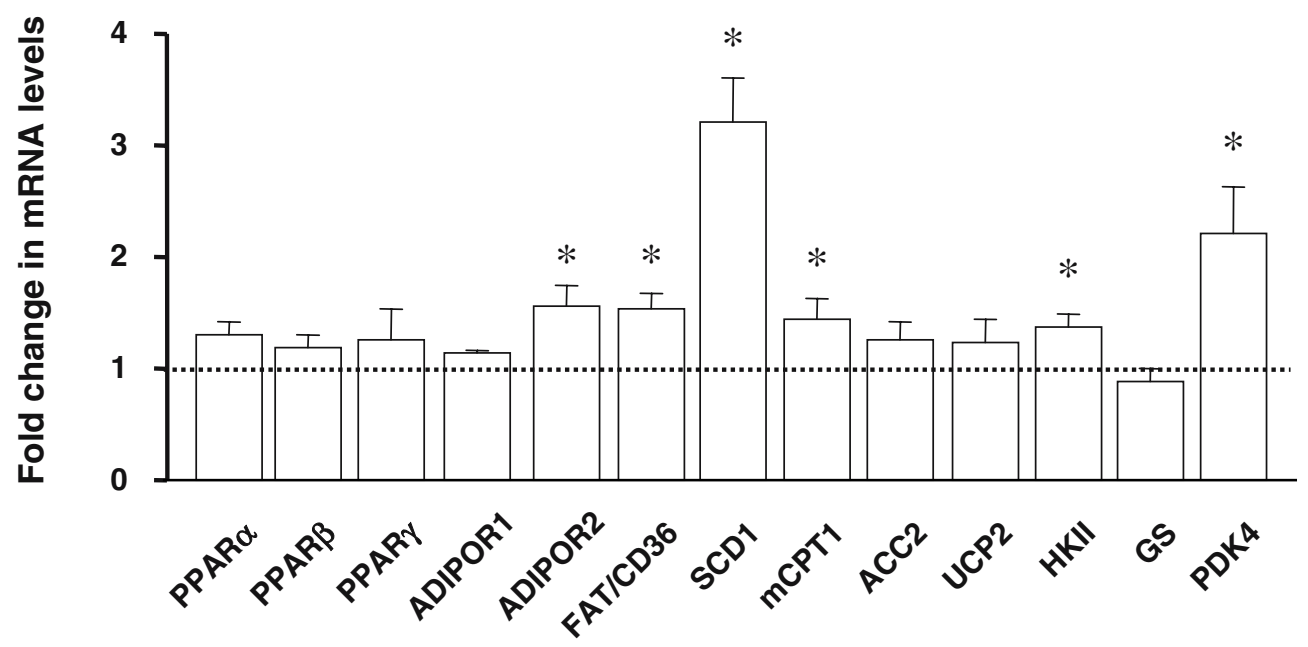

Fig. 4 Effect of LXR agonist on mRNA levels of genes involved in fatty acid oxidation and glucose metabolism in human myotubes. Differentiated myocytes were obtained from vastus lateralis skeletal muscle biopsies from healthy subjects and incubated for $48 \mathrm{~h}$ with the LXR agonist T0901317 (1 $\mu \mathrm{mol} / \mathrm{l})$ in a serum-free medium containing $5 \mathrm{mmol} / \mathrm{l}$ glucose. Data are expressed as fold change compared with the untreated condition (DMSO) and are mean $\pm \mathrm{SE}$ $(n=4) .{ }^{*} p<0.05$ vs. basal condition. PPAR Peroxisome proliferative activated receptor, $A D I P O R$ adiponectin receptor, $F A T / C D 36$ fatty acid translocase, $m C P T 1$ muscle isoform of carnitine palmitoyltransferase 1, UCP2 uncoupling protein 2, HKII hexokinase II, GS glycogen synthase, $P D K 4$ pyruvate dehydrogenase kinase 4 
after $6 \mathrm{~h}$ and a more than three-fold increase after $48 \mathrm{~h}$ (Fig. 2). The effect of LXR activation was also studied on the mRNA levels of 12 additional genes related to lipid and glucose metabolism. As shown in Fig. 4, T0901317 produced strong induction of stearoyl-CoA desaturase 1 (SCD1), the rate-limiting enzyme catalysing the conversion of saturated long-chain fatty acids into monounsaturated fatty acids. Several genes encoding proteins related to fatty acid oxidation, such as the muscle isoform of carnitine palmitoyl-CoA transferase 1, pyruvate dehydrogenase kinase 4 , fatty acid translocase and adiponectin receptor 2, were also significantly induced after $48 \mathrm{~h}$ of incubation with the LXR agonist. Hexokinase II (HKII) mRNA levels were also slightly increased, whereas there was no effect on the mRNA encoding glycogen synthase (Fig. 4). Finally, it is important to note that the expression of neither peroxisome proliferator-activated receptor $\gamma 2$ (Fig. 4) nor adiponectin, taken as adipose tissue specific markers, was significantly modified during the treatment (data not shown). This indicates that T0901317 did not produce trans-differentiation of the muscle cells into adipocytes under these experimental conditions.

The strong induction of the expression of genes encoding proteins related to lipogenesis suggested that
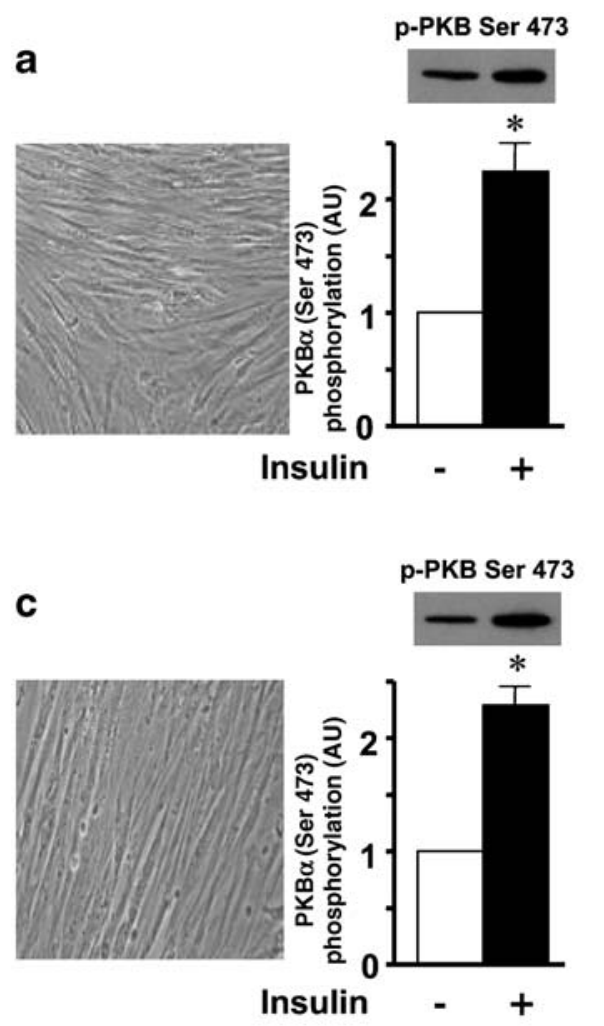

Fig. 5 Effect of LXR activation on triglyceride accumulation and PKB phosphorylation in human skeletal muscle cells. Differentiated myocytes were obtained from vastus lateralis skeletal muscle biopsies from healthy subjects and incubated with vehicle (DMSO) alone $(\mathbf{a}, \mathbf{c})$ or with $1 \mu \mathrm{mol} / 1$ of T0901317 (b, d) for $48 \mathrm{~h}$ in a serum-free medium containing $5 \mathrm{mmol} / 1$ glucose. During the last $24 \mathrm{~h}$ of incubation, cells were either maintained in $5 \mathrm{mmol} / \mathrm{l}$ glucose (a, b) or supplemented with $25 \mathrm{mmol} / 1$ glucose $(\mathbf{c}, \mathbf{d})$. After
LXR activation promoted lipid accumulation in the human muscle cells. To verify this assumption, myotubes were stained with Oil Red-O. Unexpectedly, when the cells were maintained in the standard culture medium containing $5 \mathrm{mmol} / \mathrm{l}$ glucose, there was no detectable accumulation of lipids after $48 \mathrm{~h}$ of treatment with T0901317 (Fig. 5). Under this condition, however, genes related to fatty acid metabolism were upregulated (Figs. 2 and 4). In contrast, marked accumulation of lipid droplets was observed when $25 \mathrm{mmol} / \mathrm{l}$ glucose was added during the last $24 \mathrm{~h}$ of treatment with T0901317 (Fig. 5).

Because intracellular lipid accumulation has been associated with decreased insulin signalling in rodent skeletal muscle, we evaluated the effect of the different conditions on the phosphorylation of PKB by insulin. The total protein amount of PKB was not affected in any condition (data not shown). Figure 5 clearly demonstrates that insulin normally stimulated PKB in all situations. This indicates that neither treatment with T0901317 nor lipid accumulation due to LXR-induced lipogenesis affected the response to insulin in the PKB signalling pathway in human skeletal muscle cells.
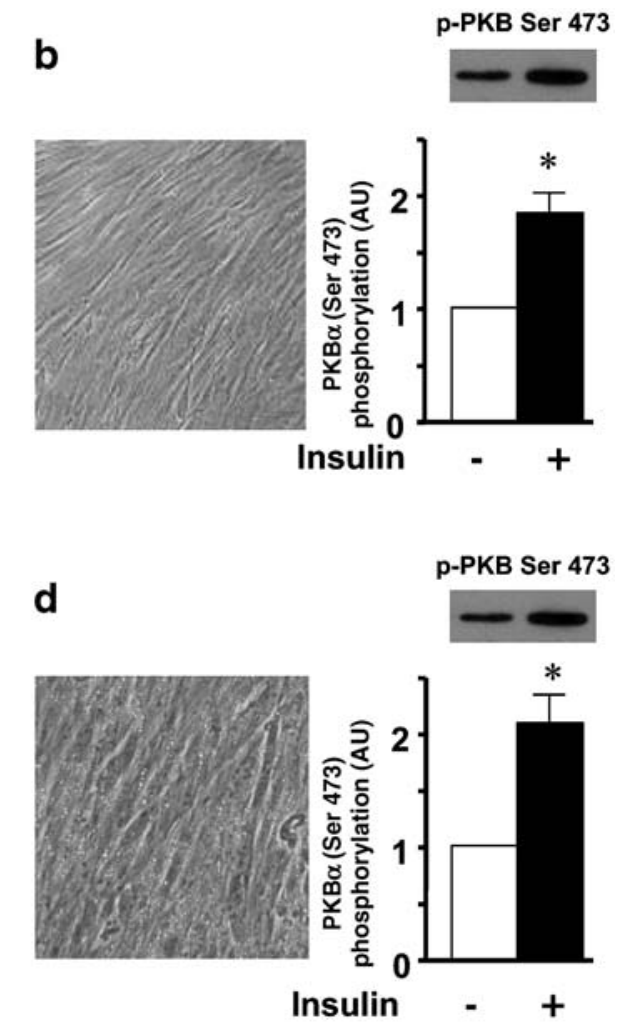

treatment, lipid accumulation was visualised by Oil Red-O staining and the effect of insulin on Ser 473 PKB phosphorylation was determined by western blotting after stimulation with $100 \mathrm{nmol} / \mathrm{l}$ insulin for $20 \mathrm{~min}(n=3)$. For the quantification of PKB phosphorylation (bars), data were normalised by the total amount of PKB determined on the same blot, as indicated in Subjects and methods. There was no difference in the total protein amount of PKB in any condition (data not shown). $A U$, Arbitrary units 
LXR activation did not improve insulin action in human muscle cells from patients

with type 2 diabetes

In differentiated myotubes prepared from diabetic patients, T0901317 induced SREBP1c mRNA levels and SREBP1 protein expression to a similar extent to what was observed in cells from control subjects, as shown in Fig. 6. Moreover, LXR activation with T0901317 also increased the mRNA expression of LXR $\alpha$, FAS and SCD1 in muscle cells from diabetic patients (data not shown).

To assess insulin action in cells treated with LXR agonists, we measured the effects of insulin on the activation of PKB and the rate of glycogen synthesis. The differentiated myotubes were incubated for $48 \mathrm{~h}$ with T0901317 $(1 \mu \mathrm{mol} / \mathrm{l})$ in the presence of $5 \mathrm{mmol} / \mathrm{l}$ glucose to avoid possible confounding effects of lipid deposition. As presented already in Fig. 5, T0901317 did not modify the effect of insulin on the phosphorylation of serine 473 of PKB in myotubes from control subjects (Fig. 7a). LXR activation, however, appeared to slightly increase, although not significantly, the amount of phosphorylated PKB in the basal state. Use of another LXR agonist (GW3965) led to the same result (data not shown). In muscle cells from patients with type 2 diabetes, the stimulatory effect of insulin was significantly reduced when compared with myotubes from control subjects. The action of insulin on PKB phosphorylation was not affected by treatment with T0901317. There was also no effect of GW3965 on insulin action in myotubes from diabetic patients (data not shown).

Regarding the metabolic action of insulin, we investigated the regulation of glycogen synthesis. Figure $7 \mathrm{~b}$ clearly shows that there was a reduction in the effect of insulin in myotubes from diabetic patients when compared with cells from control subjects. Treatment with T0901317 increased glycogen synthesis in the absence of insulin in

myotubes from both groups of subjects, but did not improve insulin action.

\section{Discussion}

Both LXR $\alpha$ and $\operatorname{LXR} \beta$ were expressed in human skeletal muscle and adipose tissue. In muscle, LXR $\beta$ was the main expressed form, being about 30 -fold more abundant than LXR $\alpha$ at the mRNA level. In contrast, the two isoforms were expressed at similar levels in adipose tissue. Importantly, there was no alteration in the mRNA expression levels of LXR $\alpha$ and LXR $\beta$ in the tissues of patients with type 2 diabetes mellitus. These data do not support a direct involvement of a defective expression of the LXRs in the observed reduction in SREBP1c levels in the muscle and the adipose tissue of the diabetic patients.

Given the recent interest in LXR ligands as potential therapeutic agents and the demonstration that one of these synthetic agonists improved glucose tolerance in a murine model of diet-induced obesity and insulin resistance [7], it was important to better characterise the effects of LXR activation on lipid metabolism and insulin action in human tissues. For this purpose, we used a model of primary cultures of differentiated skeletal muscle cells [23]. We and others have demonstrated that skeletal muscle cells from diabetic patients display several defects that are similar to those observed in vivo in skeletal muscle, including a reduced stimulation of glucose uptake and glycogen synthesis in response to insulin and altered activation of the IRS1/PI3kinase/PKB signalling pathway [23, 25, 26]. The human myotubes expressed the two LXR isoforms with a distribution similar to that in muscle biopsies. Several recent reports indicated that ligands of the LXRs (T0901317 or GW3965) induced the expression of key genes of lipogenesis and lipid metabolism, both in vivo in

Fig. 6 Effect of LXR agonist on level of SREBP1c mRNA and amount of SREBP1 protein in myotubes from patients with type 2 diabetes. Differentiated myocytes were cultured in the presence of DMSO (vehicle) or T0901317 (1 $\mu \mathrm{mol} / 1)$ for $6 \mathrm{~h}$ for the quantification of SREBP1c mRNA (a) or $48 \mathrm{~h}$ for the effect on SREBP1 protein level (b). SREBP1c mRNA (a) was quantified by quantitative realtime PCR. Data (mean \pm SE) are presented as fold change over untreated condition (DMSO). $* p<0.05$ vs. basal condition; $n=4$. b The full-length and mature forms of SREBP1 protein were determined by western blot analysis using the H160 antibody [33]. The experiment was performed in two different preparations of muscle cells from control and diabetic patients
Fold change in SREBP1c mRNA level
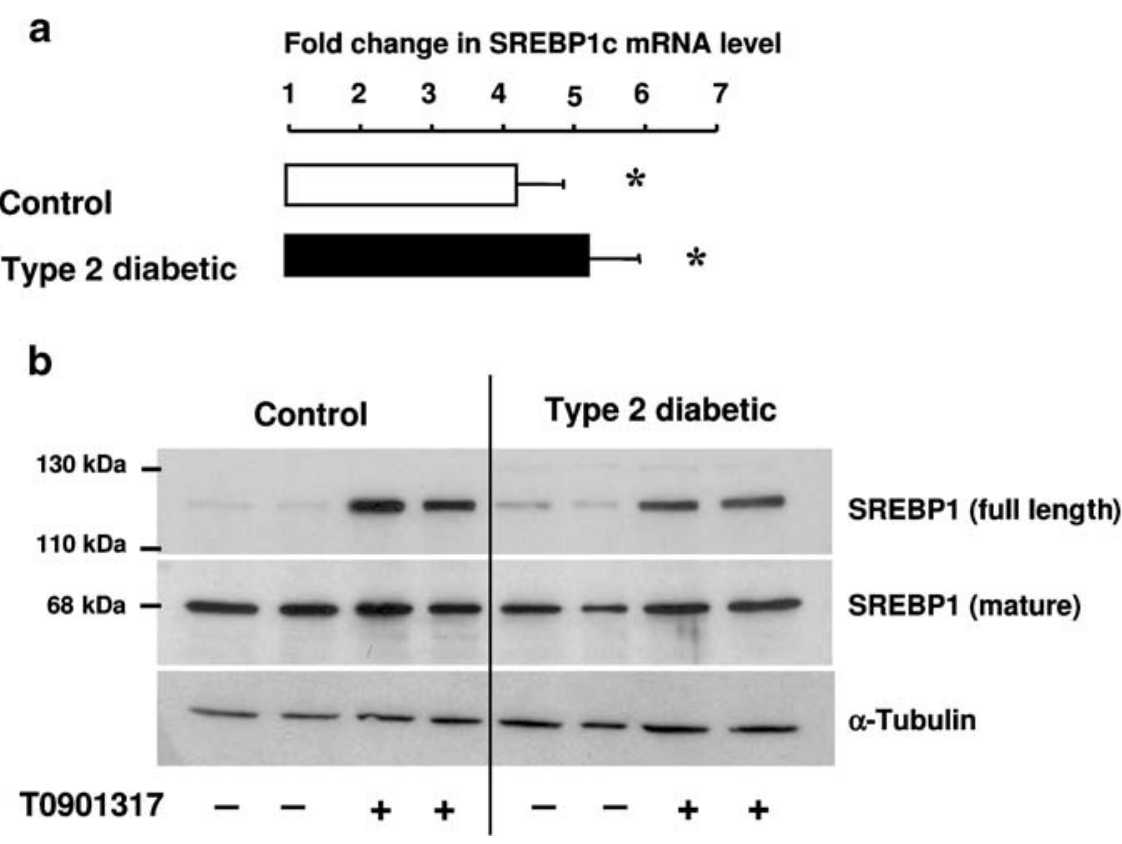

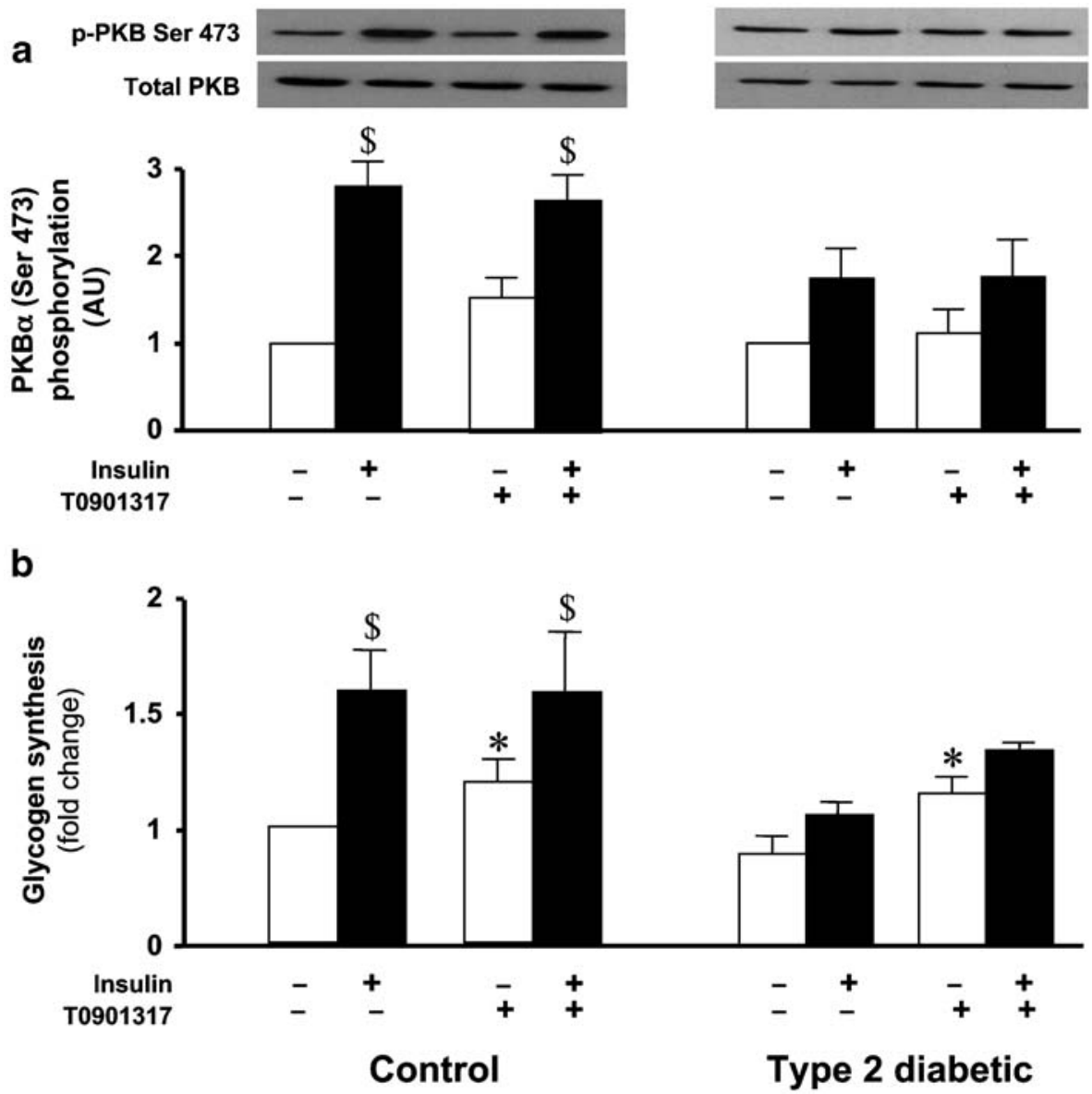

Fig. 7 Effect of LXR agonist on PKB phosphorylation and glycogen synthesis in human muscle cells from patients with type 2 diabetes. Differentiated myotubes were cultured in the presence of DMSO (vehicle) or T0901317 $(1 \mu \mathrm{mol} / \mathrm{l})$ for $48 \mathrm{~h}$ in a serum-free medium containing $5 \mathrm{mmol} / 1$ glucose. a $\mathrm{PKB}$ phosphorylation. Cells were then stimulated with insulin $(100 \mathrm{nmol} / \mathrm{l})$ for $20 \mathrm{~min}$ and total protein extract was separated by SDS-PAGE and analysed by western blot analysis for PKB phosphorylation on serine 473. Data are expressed as arbitrary units (AU) with reference to the basal condition (vehicle alone), taken as 1 in the control and in the diabetic group. In the basal condition there was no significant difference between cells from control and diabetic subjects (not

rodent skeletal muscle $[6,7,20]$ and in vitro in cultured muscle cells $[8,19]$. In the present study, we confirmed and extended these observations to differentiated human myotubes. Treatment with T0901317, which activates both $\operatorname{LXR} \alpha$ and LXR $\beta$ [6], acutely induced SREBP1c, LXR $\alpha$, FAS and SCD1 mRNA expression. The autoregulation of the gene coding for LXR $\alpha$ has been reported previously in human macrophages [31], with identification of multiple LXR response elements in the promoter [32]. Here, we confirmed the direct transcriptional action of the LXRs on SREBP1c promoter of the human SREBF1 gene. The deletion of the two LXREs located in the proximal promoter region completely suppressed the effect of T0901317 on the promoter activity. Regarding the regulation of the gene coding for FAS, the situation is probably more complex because it is well established that SREBP1 is also a strong inducer of FAS expression [33]. Combined shown). Data are mean \pm SE. ${ }^{*} p<0.05$ for the effect of insulin; $n=5$ for the control group and $n=4$ for patients with type 2 diabetes. b Glycogen synthesis. Cells were treated for $90 \mathrm{~min}$ with $100 \mathrm{nmol} / \mathrm{l}$ of insulin and then incubated for $3 \mathrm{~h}$ with $\mathrm{D}-\left[\mathrm{U}-{ }^{14} \mathrm{C}\right]$ glucose, as indicated in Subjects and methods. The amount of $\left[{ }^{14} \mathrm{C}\right]$ glucose incorporated into glycogen was determined and normalised for the amount of protein in each culture well. Data are expressed as fold change in glycogen synthesis compared with the basal condition measured with cells from control subjects and are presented as mean \pm SE, $n=4$. ${ }^{*} p<0.05$ for the effect of T0901317 in the absence of insulin, ${ }^{\$} p<0.05$ for the effect of insulin

activation by LXR directly and by the augmented SREBP1c could contribute to the observed increase in FAS transcripts. The induction of SREBP1c could also be responsible for the retarded $(48 \mathrm{~h})$ increase in the expression of other genes known to be targeted by this transcription factor, such as the genes encoding acetyl-CoA carboxylase 2 and HKII [34, 35]. However, it should be noted that whereas LXR activation promoted strong induction at the SREBP1 mRNA and precursor protein levels, the effect on the mature form of SREBP1 was less pronounced, in agreement with recent observations in rodent hepatocytes [36]. Further work is thus needed to fully elucidate the precise transcriptional regulation of the gene network induced by LXR activation in muscle cells.

It was recently reported that chronic $(96 \mathrm{~h})$ activation of LXR by T0901317 increases palmitate uptake and lipid accumulation in human myotubes [19]. These authors also 
showed that glucose uptake was increased with concomitant induction of the solute carrier family 2 (facilitated glucose transporter), members 1 and 4 (previously known as glucose transporters 1 and 4 [GLUT1, GLUT4]) [19]. Here, we demonstrate that triglyceride accumulation can also be achieved in the absence of added fatty acids. T0901317 was able to promote de novo lipogenesis in the presence of a high concentration of glucose. Glucose uptake was probably also augmented by T0901317 in our work, as supported by the increase in HKII expression and by the observed higher rate of glycogen synthesis in the absence of insulin. Taken together, these data indicate that activation of LXR could have beneficial effects on circulating fatty acid and glucose concentrations by increasing their uptake and metabolism in muscle cells. This finding is in agreement with the improvement in glucose tolerance in diet-induced obese mice treated with GW3965 [7].

Induction of de novo lipogenesis, as shown here, and increased uptake of fatty acid [19] lead, however, to the accumulation of triglycerides in the muscle cells. There is compelling evidence that intramyocellular triglyceride deposition is associated with insulin resistance [3-5]. Rather surprisingly, LXR activation did not seem to alter insulin action in human muscle cells. We found that treatment with T0901317 did not modify the effects of insulin on the activation of PKB, suggesting that the IRS1/ PI3kinase/PKB pathway was not affected in the human myotubes despite accumulation of triglycerides. Recent reports indicate that the triglycerides per se are not directly responsible for the inhibition of the insulin signalling pathway, but rather that accumulation of intermediary metabolites, such as long-chain acetyl-CoAs and diacylglycerol, via activation of protein kinase $\mathrm{C}$ isoforms, may be more directly implicated [5, 37]. The lack of a deleterious effect of LXR activation on insulin signalling in human myotubes suggests that these intermediary metabolites probably did not accumulate in the cells during triglyceride synthesis. Alternatively, it has been demonstrated that the deleterious effect of the fatty acids depends strongly upon their nature, saturated being more efficient than polyunsaturated fatty acids [38]. Because the latter are much more easily incorporated into triglycerides, it has been hypothesised that accumulation of triglycerides may protect against lipotoxicity to prevent fatty acid overload [38]. The robust induction of SCD1 mRNA by LXR agonists in muscle cells might favour the synthesis of unsaturated fatty acids, thus protecting the cells from toxic effects through the facilitation of triglyceride formation. Although this hypothesis remains to be evaluated, all these data suggest that LXR activation, by increasing the uptake of fatty acids and glucose and by modifying their metabolism in skeletal muscle $[6,8,19]$ and in other tissues [39], could contribute to the amelioration of glycaemic control and circulating fatty acid concentrations [7], at least acutely, without deleterious effects on insulin action.

It has been shown recently that the effect of LXR activation on fatty acid uptake and lipid accumulation is enhanced in myotubes prepared from patients with type 2 diabetes [19]. Insulin signalling and insulin action on glucose metabolism, including glucose uptake and glycogen synthesis, are profoundly altered in this cell model [25, $26,40]$. We therefore measured the effect of LXR agonists on insulin action in human myotubes from patients with type 2 diabetes. Our data demonstrated that LXR activation did not improve the response to insulin in myotubes prepared from patients with type 2 diabetes. This lack of effect was similarly found when measuring the effects of insulin on the activation of PKB or on the stimulation of glycogen synthesis. These data suggest, therefore, that there is no direct effect of the LXRs on the action of insulin in human muscle cells. In addition, we did not find any effect of LXR agonists on the mRNA expression of the key proteins of insulin signalling, such as insulin receptor, IRS1, P85 $\alpha$ PI3kinase, and phosphatase and tensin homolog deleted on chromosome 10 (PTEN) (data not shown).

In summary, our study shows that both LXR isoforms are expressed in human muscle and adipose tissue and that there is no alteration in patients with type 2 diabetes. In differentiated human skeletal muscle cells, activation of LXRs leads to marked induction of lipogenesis and accumulation of triglycerides without affecting insulin action. Furthermore, LXR agonists do not appear to have significant effects on the action of insulin in muscle cells from insulin-resistant patients with type 2 diabetes. These data thus suggest that treatment with LXR agonists may lead to increased utilisation of lipids and glucose. However, the long-term consequences of triglyceride accumulation in the tissues should be evaluated before the development of effective LXR-based therapeutic agents.

Acknowledgements The authors would like to thank J. Peyrat, C. Urbain, E Loizon and V. Berbe for excellent technical assistance. This work was supported in part by research grants from INSERM (PNRD 2004). D. Cozzone, N. Dif and C. Debard are recipients of doctoral fellowships from the Ministère de l'Enseignement Supérieur et de la Recherche.

Duality of interest The study was initiated and led by the investigators from INSERM Unit 449, who received funds from Fournier-Pharma for the running costs of the study. D. Pruneau is employed by Fournier-Pharma. There was no conflict of interest for the use of the LXR agonist T0901317, which is a published reference molecule.

\section{References}

1. Kelley DE, Mandarino LJ (2000) Fuel selection in human skeletal muscle in insulin resistance: a reexamination. Diabetes 49:677-683

2. Kelley DE, Simoneau JA (1994) Impaired free fatty acid utilization by skeletal muscle in non-insulin-dependent diabetes mellitus. J Clin Invest 94:2349-2356

3. McGarry JD (2002) Banting lecture 2001: dysregulation of fatty acid metabolism in the etiology of type 2 diabetes. Diabetes 51:7-18

4. Shulman GI (2000) Cellular mechanisms of insulin resistance. J Clin Invest 106:171-176 
5. Hegarty BD, Furler SM, Ye J, Cooney GJ, Kraegen EW (2003) The role of intramuscular lipid in insulin resistance. Acta Physiol Scand 178:373-383

6. Schultz JR, Tu H, Luk A et al (2000) Role of LXRs in control of lipogenesis. Genes Dev 14:2831-2838

7. Laffitte BA, Chao LC, Li J et al (2003) Activation of liver X receptor improves glucose tolerance through coordinate regulation of glucose metabolism in liver and adipose tissue. Proc Natl Acad Sci USA 100:5419-5424

8. Muscat GE, Wagner BL, Hou J et al (2002) Regulation of cholesterol homeostasis and lipid metabolism in skeletal muscle by liver X receptors. J Biol Chem 277:40722-40728

9. Auboeuf D, Rieusset J, Fajas L et al (1997) Tissue distribution and quantification of the expression of mRNAs of peroxisome proliferator-activated receptors and liver $\mathrm{X}$ receptor-alpha in humans: no alteration in adipose tissue of obese and NIDDM patients. Diabetes 46:1319-1327

10. Repa JJ, Liang G, Ou J et al (2000) Regulation of mouse sterol regulatory element-binding protein-1c gene (SREBP-1c) by oxysterol receptors, LXRalpha and LXRbeta. Genes Dev 14:2819-2830

11. Foretz M, Guichard C, Ferre P, Foufelle F (1999) Sterol regulatory element binding protein-1c is a major mediator of insulin action on the hepatic expression of glucokinase and lipogenesis-related genes. Proc Natl Acad Sci USA 96:12737-12742

12. Foufelle F, Ferre P (2002) New perspectives in the regulation of hepatic glycolytic and lipogenic genes by insulin and glucose: a role for the transcription factor sterol regulatory element binding protein-1c. Biochem J 366:377-391

13. Osborne TF (2000) Sterol regulatory element-binding proteins (SREBPs): key regulators of nutritional homeostasis and insulin action. J Biol Chem 275:32379-32382

14. Yoshikawa T, Shimano H, Amemiya-Kudo M et al (2001) Identification of liver $X$ receptor-retinoid $X$ receptor as an activator of the sterol regulatory element-binding protein $1 \mathrm{c}$ gene promoter. Mol Cell Biol 21:2991-3000

15. DeBose-Boyd RA, Ou J, Goldstein JL, Brown MS (2001) Expression of sterol regulatory element-binding protein 1c (SREBP-1c) mRNA in rat hepatoma cells requires endogenous LXR ligands. Proc Natl Acad Sci USA 98:1477-1482

16. Ducluzeau PH, Perretti N, Laville M et al (2001) Regulation by insulin of gene expression in human skeletal muscle and adipose tissue. Evidence for specific defects in type 2 diabetes. Diabetes 50:1134-1142

17. Becard D, Hainault I, Azzout-Marniche D, Bertry-Coussot L, Ferre P, Foufelle F (2001) Adenovirus-mediated overexpression of sterol regulatory element binding protein-1c mimics insulin effects on hepatic gene expression and glucose homeostasis in diabetic mice. Diabetes 50:2425-2430

18. Guillet-Deniau I, Mieulet V, Le Lay S et al (2002) Sterol regulatory element binding protein-1c expression and action in rat muscles: insulin-like effects on the control of glycolytic and lipogenic enzymes and UCP3 gene expression. Diabetes 51:1722-1728

19. Kase ET, Wensaas AJ, Aas V (2005) Skeletal muscle lipid accumulation in type 2 diabetes may involve the liver $\mathrm{X}$ receptor pathway. Diabetes 54:1108-1115

20. Chisholm JW, Hong J, Mills SA, Lawn RM (2003) The LXR ligand T0901317 induces severe lipogenesis in the $\mathrm{db} / \mathrm{db}$ diabetic mouse. J Lipid Res 44:2039-2048

21. Chavez JA, Summers SA (2003) Characterizing the effects of saturated fatty acids on insulin signaling and ceramide and diacylglycerol accumulation in 3T3-L1 adipocytes and C2C12 myotubes. Arch Biochem Biophys 419:101-109

22. Laville M, Auboeuf D, Khalfallah Y et al (1996) Acute regulation by insulin of phosphatidylinositol-3-kinase, Rad, Glut 4, and lipoprotein lipase mRNA levels in human muscle. $\mathrm{J}$ Clin Invest 98:43-49
23. Bouzakri K, Roques M, Gual P et al (2003) Reduced activation of phosphatidylinositol-3 kinase and increased serine 636 phosphorylation of insulin receptor substrate-1 in primary culture of skeletal muscle cells from patients with type 2 diabetes. Diabetes 52:1319-1325

24. Rieusset J, Bouzakri K, Chevillotte E et al (2004) Suppressor of cytokine signaling 3 expression and insulin resistance in skeletal muscle of obese and type 2 diabetic patients. Diabetes 53:2232-2241

25. Henry RR, Ciaraldi TP, Abrams-Carter L et al (1996) Glycogen synthase activity is reduced in cultured skeletal muscle cells of non-insulin-dependent diabetes mellitus subjects. Biochemical and molecular mechanisms. J Clin Invest 98:1231-1236

26. Gaster M, Petersen I, Hojlund K, Poulsen P, Beck-Nielsen H (2002) The diabetic phenotype is conserved in myotubes established from diabetic subjects: evidence for primary defects in glucose transport and glycogen synthase activity. Diabetes 51:921-927

27. Chomczynski P, Sacchi N (1987) Single-step method of RNA isolation by acid guanidinium thiocyanate-phenol-chloroform extraction. Anal Biochem 162:156-159

28. Debard C, Laville M, Berbe V et al (2004) Expression of key genes of fatty acid oxidation, including adiponectin receptors, in skeletal muscle of type 2 diabetic patients. Diabetologia 47:917-925

29. Zabarovsky ER, Gizatullin R, Podowski RM et al (2000) NotI clones in the analysis of the human genome. Nucleic Acids Res 28:1635-1639

30. Al-Khalili L, Chibalin AV, Kannisto K et al (2003) Insulin action in cultured human skeletal muscle cells during differentiation: assessment of cell surface GLUT4 and GLUT1 content. Cell Mol Life Sci 60:991-998

31. Whitney KD, Watson MA, Goodwin B et al (2001) Liver X receptor (LXR) regulation of the LXRalpha gene in human macrophages. J Biol Chem 276:43509-43515

32. Laffitte BA, Joseph SB, Walczak R et al (2001) Autoregulation of the human liver $\mathrm{X}$ receptor alpha promoter. Mol Cell Biol 21:7558-7568

33. Kim JB, Spiegelman BM (1996) ADD1/SREBP1 promotes adipocyte differentiation and gene expression linked to fatty acid metabolism. Genes Dev 10:1096-1107

34. Oh SY, Park SK, Kim JW et al (2003) Acetyl-CoA carboxylase beta gene is regulated by sterol regulatory element-binding protein-1 in liver. J Biol Chem 278:28410-28417

35. Gosmain Y, Lefai E, Ryser S, Roques M, Vidal H (2004) Sterol regulatory element-binding protein-1 mediates the effect of insulin on hexokinase II gene expression in human muscle cells. Diabetes 53:321-329

36. Hegarty BD, Bobard A, Hainault I (2005) Distinct roles of insulin and liver $X$ receptor in the induction and cleavage of sterol regulatory element-binding protein-1c. Proc Natl Acad Sci USA 102:791-796

37. Montell E, Turini M, Marotta M et al (2001) DAG accumulation from saturated fatty acids desensitizes insulin stimulation of glucose uptake in muscle cells. Am J Physiol Endocrinol Metab 280:E229-E237

38. Listenberger LL, Han X, Lewis SE et al (2003) Triglyceride accumulation protects against fatty acid-induced lipotoxicity. Proc Natl Acad Sci USA 100:3077-3082

39. Cao G, Liang Y, Broderick CL et al (2003) Antidiabetic action of a liver $\mathrm{x}$ receptor agonist mediated by inhibition of hepatic gluconeogenesis. J Biol Chem 278:1131-1136

40. Bouzakri K, Roques M, Debard C et al (2004) WY-14643 and 9-cis-retinoic acid induce IRS-2/PI 3-kinase signalling pathway and increase glucose transport in human skeletal muscle cells: differential effect in myotubes from healthy subjects and type 2 diabetic patients. Diabetologia 47:1314-1323 